\title{
Acculturative Experiences Among Indonesian Graduate Students in Dutch Higher Education
}

\author{
Amirul Mukminin \\ Jambi University, Indonesia
}

\begin{abstract}
The intent of this enquiry, within the theoretical frame of the acculturation stress model, was to describe the results from research on the lived experiences of Indonesian international graduate students at two Dutch public research universities in the northern part of the Netherlands. The students came from diverse backgrounds and experiences in search of quality education for their future career development. The data collection was conducted from 24 Indonesian students on their experiences from their earliest term throughout their education in the Netherlands. Data were gathered through a demographic profile survey and audio recorded in exhaustive interviews. An analysis of the data revealed common issuesunanticipated educational stressors, unimagined social stressors, language issues, and loneliness/isolation. The participants also described potential strategies for coping with these stressors. The common themes symbolize everyday experiences that Indonesian master's students faced throughout their acculturative process from the earliest term and over time. Implications, future research, and limitations are discussed.
\end{abstract}

Keywords: acculturation, Dutch higher education, international students 


\section{INTRODUCTION}

For some Indonesian students, Dutch postsecondary institutions have been a destination to pursue their educational careers in order to improve their capacity, skills, and knowledge to seize new opportunities in Indonesia or in other countries. According to the Open Doors report issued once a year by the Institute for International Education (IIE) with support from the U.S. Department of State's Bureau of Educational and Cultural Affairs, in the 2007-2008 academic year, Indonesia was still one of the top 10 sending places of origin of total international student enrollment in the Netherlands with 1,450 of 48,900 students (IIE, 2017). In the 2008-2009 academic year, Indonesia was still part of the top 10 sending countries with 1,350 of 76,000 students. However, from the 2009-2010 to the 2016-2017 academic years, the number of Indonesian students studying in Dutch higher education decreased, and Indonesia is no longer part of the top 10 sending countries (IIE, 2017). The decline of Indonesian students studying in Dutch institutions of higher education has raised important questions for educators in the Netherlands: Is the decline in enrollment of Indonesian students in Dutch higher education related to the acculturative problems or difficulties students face during their acculturative process at their host universities? If it is related to the acculturative problems, to what extent do Indonesian students experience the acculturative problems or stressors at their host universities?

Although an extensive quantity of former investigations has addressed the acculturative issues suffered by international students, many of the studies have generally concentrated on international students or have clustered Asian international students from diverse nations into one group (Mukminin 2012; Mukminin \& McMahon, 2013). Not much research, however, specifically explores the experiences of Indonesian graduate in Dutch higher education institutions. In the Netherlands, one study on Indonesian student engineers' English proficiency and academic success in international postgraduate education was conducted by Vinke and Jochems (1993), who found that Indonesian students' age and English proficiency affected the ability to earn grades and to succeed in a postgraduate English-medium program.

While Vinke and Jochems's (1993) study might be useful for understanding what Indonesian students experienced during their acculturative process in the Netherlands, the world has changed considerably since 1993, which further justifies the need for such research. The world has experienced dramatic cultural, social, and political changes that have altered issues of content, access to, and means of communication, thereby influencing acculturation of Indonesian students studying in Dutch higher education institutions. Also, due to technological advancements in Internet access and in mediums of communication such as Facebook, email, YouTube, Google, 
and Wikipedia, information about the cultures of other countries is now easily accessible worldwide, which may greatly facilitate Indonesians getting knowledge on other cultures. With the dramatic changes that have taken place in the past two decades, the degree of unfamiliarity and uncertainty (Mukminin, 2012) that Indonesian graduate students have faced in their new academic and social culture in the Netherlands might now be significantly lower.

The purpose of this enquiry, within acculturative stress theory (Berry, 2006; Berry, Kim, Minde, \& Mok, 1987), can be summarized in two ways: First, this enquiry was an effort to fill a gap in the literature of Asian international students' acculturation experiences, specifically those of Indonesian international students on Dutch campuses. Second, by investigating students from the same cultural backdrops, the goal of the study was to understand the experiences of the Indonesian international students' acculturative processes through the lenses of acculturative stress theory (Berry, 2006). Mainly, the study sought to understand to what extent acculturative problems or stressors confront Indonesian international students during their studies in the Netherlands. The following questions directed this study.

1. What have Indonesian graduate students experienced academically and socially during their acculturative process in Dutch higher education institutions?

2. What are the major sources of acculturative problems and stressors experienced by Indonesian graduate students during their first term and over time in Dutch higher education institutions?

3. How have Indonesian graduate students dealt with those acculturative stressors during the first term and over time in Dutch higher education institutions?

\section{THEORETICAL FRAMEWORK}

To better understand and portray Indonesian graduate students' educational and social experiences during their acculturative processes at Dutch higher education institutions, the acculturation stress model described by Berry, Kim, Minde, and Mok (1987) and Berry (2006) offers a lens for this study. The notion of acculturation stress, which was initially introduced by the Canadian psychologist Berry (1970), refers to general and cultural stress reactions associated with transitioning to a new culture. Berry (2006) argued that when acculturation experiences bring about problems, at the personal level, one of the outcomes is "acculturative stress," which happens as "a stress 
reaction in response to life events that are rooted in the experience of acculturation" (p. 294).

The studies in Berry (2006) and Berry et al. (1987) argue that the acculturating persons are confronting acculturative stressors due to intercultural and endless interactions that cannot be resolved quickly by merely adjusting to the new culture. Furthermore, Berry and colleagues stated that the larger the dissimilarities between two cultures, the greater the stress. Such situations lead acculturating persons to have identity confusion, loss of self-confidence, and lowered mental health status (e.g., confusion, anxiety, depression, and feelings of marginality and alienation). However, although such acculturative stressors could be inevitable and result in social and behavioral changes, each group and person faces the acculturative process in diverse ways: "Acculturation sometimes enhances one's life chances and mental health, and sometimes virtually destroys one's ability to carry on" (Berry et al., 1987, p. 493).

The acculturation experience is faced not only by international students but more broadly by people in native settlements, sojourners, or migrant communities. These individuals face adjustments in their habitual patterns and internal qualities to varying degrees (Berry et al., 1987, as cited in Mukminin, 2012). An acculturating person may confront a varying degree of stressors. During the acculturating experience, the adjustments in habitual patterns may become sources of stress for some people, but for other people, the changes may become opportunities (Berry et al., 1987, as cited in Mukminin, 2012). However, the correlations among the acculturative experiences, stressors, and acculturative stress are influenced by two crucial things. First, according to Berry et al. (1987, p. 494), the correlations among the three "are probabilistic rather than deterministic." The correlations may happen, but they are not guaranteed, nor permanent. Second, the correlations are contingent on moderating factors, which may affect the degree and route of the correlations (Berry et al., 1987, as cited in Mukminin, 2012).

The first factor, according to Berry et al. (1987), is related to the host society's nature - if the society holds a multicultural/pluralistic ideology or a cultural norm. The second factor is related to the kind of the acculturating group, including ethnic groups, immigrant groups, sojourners, or native settlements. For instance, acculturating persons (e.g., international students) who undergo a short-range contact with their host and have no permanent social support may face extra psychological health concerns, as opposed to individuals who are more permanently settled such as ethnic or immigrant groups. According to Berry et al. (1987) and Berry (2006), the next factor is the kind of acculturative strategies, such as assimilation, integration, separation, and marginalization, that will be employed by acculturating persons coming into the new setting. Each individual faces acculturative 
experiences in dissimilar methods, which will influence his or her acculturation process (Berry, 2006). Finally, the factor that may modify the relationships among the three is associated with the demographic, social, and psychological qualities of the acculturating individuals, such as educational and socioeconomic status backgrounds, maturity, gender, length of stay, and prior cross-cultural experiences.

The acculturation stress model of Berry and his colleagues (1987) and Berry (2006) can be used to understand the experiences of the Indonesian international students' acculturative process. Mainly, it will offer insight into the extent acculturative problems or stressors confront Indonesian international students from various experiences and backgrounds from their earliest term and over time in the Netherlands.

\section{RESEARCH METHOD}

\section{Design of the Study}

Experience is not objective; hence, the quantitative approaches of inquiry such as experiments or surveys may not give detailed evidence to achieve the purpose of this study (Mukminin, 2012; Mukminin \& McMahon, 2013). For this inquiry, a qualitative phenomenological approach was used to understand the lived experiences of the Indonesian international students' acculturative processes in Dutch higher education. The main purposes of a phenomenological inquiry are to understand in what way one or more persons undergo a phenomenon and to look at detailed narratives of their experiences, reflections, and perspectives to find meaning (Moustakas, 1994; Patton, 1990).

Scholars such as Moustakas (1994) and Patton (1990) recommended that any scholar who intends to utilize the phenomenological approach should understand the philosophical standpoints behind this tradition. Phenomenology as a philosophical approach was originally from Husserl (as cited in Patton, 1990), a philosopher and mathematician from Germany. A phenomenological approach could be associated with either,

(1) ... a focus on what people experience and how they interpret the world (in which case one can use interviews without actually experiencing the phenomenon oneself) or (2) a methodological mandate to actually experience the phenomenon being investigated (in which case participant observation would be necessary). (p. 70)

This inquiry focused on the first aspect of "what people experience and how they interpret the world" (p. 70). To address this aspect, Indonesian 
international students from various experiences and backgrounds were interviewed about (1) what they underwent educationally and socially during their acculturative processes arising from nonstop, firsthand contact with a new culture from their earliest term and over time in Dutch higher education, (2) the main causes of acculturative stressors resulting in acculturative stress that they experienced, and (3) in what way they have coped with the acculturative stressors from their earliest term and over time in Dutch higher education.

\section{Research Site and Sampling Procedures}

The sites for this inquiry were two Dutch national research universities in the northern part of the Netherlands. To find individual cultural transformations and acculturation results necessitates "sampling a population and studying individuals who are variably involved in the process of acculturation" (Berry, 2006, p. 289). For a phenomenological inquiry, the importance is not about having a large number of research participants, but about the processes of data collection for detailed accounts of human experience. Each phenomenological inquiry calls for research participants who can offer experiences of the phenomenon being explored (Moustakas, 1994). Specifically, the key matter is to describe the meanings of the lived experiences from individuals undergoing the phenomenon under study by collecting data through in-depth interviews with five to 25 people (Creswell, 2007; Polkinghorne, 1989).

Following Creswell's (2007), Moustakas's (1994), and Polkinghorne's (1989) idea concerning the ideal number of research participants for a phenomenological inquiry, 24 Indonesian international students agreed to take part in the study. All were master's students. For the first Dutch public research university, there were 11 master's students consisting of six female and five male students. In the second Dutch public research university, 13 master's students consisting of four female and nine male students were involved in this study. Among the participants, 18 students majored in social sciences and six majored in agriculture. All participants in this study received a full scholarship either from the Dutch government or from the Indonesian government. Additionally, all of them were enrolled in a 2-year master's program.

The participants were recruited for inquiry with the support from the Association of Indonesian Student in the Netherlands at each research site. The invitation letter stating the purpose of study was given to the Indonesian Student Association head, who then communicated with the research participants by emails that described the intent of the inquiry, and requested their approval to take part in the inquiry. This study concentrated on second- 
year master's students because they have already experienced the Dutch academic and social atmospheres. Participants received a demographic background survey and an informed consent form. The participants were Aja, Nita, Arif, Ayu, Debi, Diyan, Emilian, Ester, Fikra, Hermadian, Indran, Ita, Jimmian, Murmani, Mujian, Nelasi, Rifkian, Riyana, Silvan, Wardani, Winartoni, Wiwidayu, and Zai (pseudonyms).

Individuals are the key data source in this study. However, in the Netherlands, the process of an Institutional Review Board approval is not common, so they received an informed consent form and pseudonyms have been used to disguise the participants' identities. All participation was voluntary, and statements were confidential. All participants agreed to allow their data from the interviews to be used.

\section{Data Collection}

In the phenomenological approach, the researcher seeks to better understand the potential meaning of the individual's accounts, perspectives, and reflections of their experiences (Creswell, 2007; Merriam, 1998; Moustakas, 1994; Patton, 1990), which necessitates careful data gathering. The researchers must collect data from individuals undergoing the phenomenon under inquiry (Moustakas, 1994). Particularly, Moustakas recommended that any scholar desiring to carry out detailed interviews should consider using natural or informal interviewing techniques, unrestricted questions, or a topical-directed interview. Going along with Moustakas' (1994) idea concerning types of interviews, this study relied on informal or natural interviewing and unrestricted or open-ended questions with a broad directed interview protocol. Two rounds of interviews were conducted with 24 participants. For the first round, every interview was between 60 and 90 minutes. For the second round, every interview was between 90 and 100 minutes. All interview sessions were in English because all participants wanted to be interviewed in English.

By using a voice recorder, participants' responses were digitally captured. All interview data were documented with the participants' consent. Directed by a broad interview protocol, all research participants talked about their lived experiences educationally and socially during their acculturative processes arising from nonstop, firsthand contact with a new culture from their earliest term and over time in Dutch higher education. They also discussed the major sources of acculturative problems and stressors and how they handled those stressors. 


\section{Data Analysis}

In a phenomenological inquiry, Husserl (1859-1938) established epoché or bracketing as a central process of phenomenological inquiry in which each predetermined perception is avoided (Moustakas, 1994). For the data analysis, researchers must avoid predetermined notions in order to better comprehend the lived experiences of research participants. Horizontalization is also necessary, which itemizes every important account pertinent to the themes and gives it the same value (Moustakas, 1994). Additionally, important accounts were clustered into meaning units or themes, eliminating repetitive data (Moustakas, 1994).

During this process of data analysis, personal textual description was identified for every participant, such as verbatim samples from the recorded interview data (Moustakas, 1994). Then, tentative themes emerged, such as academic stressors (e.g., mismatches between home and host experiences, the different and challenging Dutch educational system, the amount of schoolwork within a restricted time, the Dutch classroom environment), nonacademic stressors (e.g., informal relationships between professors and students, unfair treatment from professors), language stressors (e.g., speaking anxiety, silent participation, no confidence to present academic tasks), individual stressors (e.g., discriminatory treatment on campus, feeling isolated from others), financial concerns, and potential solutions (e.g., avoiding seeking counseling from the host university, supportive network of Indonesian student association on campus).

To address the credibility and accuracy of the data and interpretations, verbatim samples from the recorded interview data were integrated in the results (Abrar et al., 2018; Mukminin, Ali, \& Ashari, 2015). Additionally, all interview data and results were sent to the participants for their agreement and feedback (see Mukminin, Rohayati, Putra, Habibi, \& Aina, 2017; Mukminin, Kamil, Muazza, \& Haryanto, 2017). All of participants permitted the use of their data in this report.

\section{FINDINGS}

Relying on the theoretical framework of the acculturation stress model from Berry (2006) and Berry and his colleagues (1987), this study was intended to describe the lived experiences of Indonesian international graduate students from their earliest term and over time at two Dutch public research universities in the northern part of the Netherlands. Several interconnected and multifaceted themes with subthemes were discovered based on the data analyses. The primary persistent themes were unanticipated educational stressors (e.g., unfamiliarity with content knowledge, mismatches 
between home and host experiences, an unexpected amount of schoolwork within a restricted time, unaccustomedness with the Dutch classroom environment), unimagined social stressors (e.g., surprising and informal relationships between professors and students, biased treatment from professors), language issues, and loneliness/isolation. However, students indicated that financial stress was not a primary concern. They had strategies for coping with acculturative stressors (e.g., relying on a family network, supportive family members who live in Indonesia, or a supportive network of Indonesian student association on and off campus, and avoiding seeking counseling from the host university). The themes and subthemes symbolize everyday experiences Indonesian international master's students faced throughout their acculturative experiences at two Dutch public research universities.

\section{Unanticipated Educational Stressors}

This theme and its subthemes capture acculturative stressors or stressful life events resulting from academic issues experienced in a new culture during the first term at a host university. Three important subthemes appeared from the interviews: (a) unfamiliarity with content knowledge based on mismatches between home and host experiences, (b) an unexpected amount of schoolwork within a restricted time, and (c) unaccustomedness with the Dutch classroom environment.

\section{Unfamiliarity with Content Knowledge: Mismatches Between Home and Host Experiences}

Owing to the dissimilarities between Indonesian and Dutch educational systems, all Indonesian students in spite of their backgrounds voiced that they did not have enough knowledge on the topics being discussed in the classroom. It was worsened by the fact that they were required to fully engage in discussions while they were not familiar with the subject matters being delivered by the professors. Because of this unfamiliarity, participants were forced to learn this situation, which led them to be stressed during their first term. For example, Nita described her encounters throughout the first year around content knowledge issues:

The quality of the program is good, but in the first term, I was shocked with the system here. I was blank, really blank about the lectures. I had nothing to say, I just sat down and listened to the lecturer.

Likewise, Diyan spoke of unfamiliarity with content knowledge: 
You know, this is my future, but during the first term, it was the most stressing time for me, I could not say even single word. It was because all the topics were about Dutch and Europe.

Additionally, Zai reflected,

I was required to take four courses in the first term, it was like full of burden, I felt pressure every day. But I had to go on for my career.

The data from interviews showed that Indonesian students were unsuccessful in fully participating in classroom discussions owing to their problems in comprehending the lecture content. However, although these experiences were stressful, the transcripts of the interviews indicated that no student wanted to go back to Indonesia. In other words, no students wanted to stop studying at their host universities although they faced some problems. They continued their studies until they completed them. They tried to work hard to succeed in the subjects during the first term because they thought the program would make a difference for their career when they went back to Indonesia after their graduation.

\section{An Unexpected Amount of Schoolwork Within a Restricted Time}

Another educational stressor that participants encountered during their first term, regardless of their majors, was the amount of homework given. They felt stressed to comprehend a large number of research articles or books assigned within a restricted timeframe. All participants expressed that they required more time to carry out multiple tasks. Common across all participants, Arif had problems related to doing multiple tasks:

I took four courses, I was exhausted, I spent the whole day in the library, just to do various tasks and assignments. I even did not know if it was Monday or Sunday. Every day was the same.

Likewise, Debi reflected,

Time was limited; it was stressful here in my new life. I tried my best, but the work never ended. It was too much.

Also, Hermadian felt overwhelmed as he struggled to manage various assignments:

It was a stressful moment in my life, I was scared, I could not meet the expectations as the system is different from 
Indonesia, but you know I just want to finish this program for my future career back home.

All participants strongly voiced that an unpredicted amount of coursework within a constrained time influenced their life in the new academic culture. However, they thought their educational adventure was important for their future life in Indonesia.

\section{Unaccustomedness with the Dutch Classroom Environment}

Another concern that participants shared during the interviews was unaccustomedness with the Dutch classroom environment. Although all participants respected the Dutch classroom environment where active participation in classroom was required to share their ideas and opinions with other students, it became one of the major stressors impacting on their full engagement. For example, Winartoni expressed,

I feel too nervous to speak in front of other students from other cultures. If I could, I wanted to keep silent.

Similarly, Nelasi explained,

The topics were too Dutch, I was stressed to start talking, I was afraid of making mistakes.

Silvan also reported,

My professor called my name and asked my ideas on the topic being discussed. It surprised me and I was shocked. It was not common in my country.

For Indonesian students, their difficulties in actively engaging in the classroom discussion might be influenced by the academic culture in Indonesia that teachers are typically active while students are more passive during the lectures.

\section{Unimagined Social Stressors}

Across all 24 cases, many participants testified that they faced some kind of unimagined social stressors during their first term at their host universities. The unimagined social stressors (e.g., surprising and informal relationships between professors and students and biased treatment from professors) occurred due to the differences between Indonesian and Dutch society regarding social relationships on campus. These unimagined social stressors seemed to take part in Indonesian international graduate students' acculturative processes in their host campuses. 
The participants reported that during the first term, they were surprised with the substantial differences in relationships between professors and students in Indonesia and in the Netherlands. Indonesian international graduate students testified that they were surprised with the types of informal or casual relationships between professors and students both inside and outside classrooms. They experienced or encountered problems establishing a supportive bond with Dutch students and professors. Contrasting with their home university, at their host university, participants reported that there was not as much of power distance between students and professors in the Netherlands. Regarding this issue, Murmani, a male interviewee and Wardani, a female participant noted,

I think most [Dutch professors] are very informal inside and outside classroom. I was shocked with this kind of situation. It is totally different from my country where they [professors] are quite formal. Here, they even invite me to talk the topics of lecturers after the class. I was not used to having this kind of academic relationships. So, I felt nervous every time, I wanted to talk with them [Dutch professors].

During the first term, I was stressed to adjust to the academic relationship here at my host university. I felt it was impolite if I just called my professors' names in the class. They [Dutch professors] are older than I.

The rest of the participants reported the same stories related to the considerable differences in relationships between professors and students in Indonesia and in the Netherlands during the first term.

\section{Biased Treatment from Professors}

The transcripts of the interviews demonstrated that although all students realized that it was difficult to get the highest grade due to the challenging academic workload during the first term in their new culture, they tried hard to participate in all academic activities related to the courses that they were taking. However, they perceived a biased treatment from their professors in terms of final grades. Across all 24 cases, most students were dissatisfied with the ways that their professors handled their final grades. For example, Arif described his dissatisfaction with his professor's biased treatment.

I liked all of the courses that I took, but I was shocked with the treatment [grades] that I got. I just got a 5, 6 for almost 
courses that took. I thought the professors ignored my backgrounds.

In Hermadian's case, he found that his professors focused too much on local students. He said,

I was shocked and anxious with the fact that they [professors] liked giving me a passing grade. It is kind of a demotivating grade, but all my local friends got a good grade.

Another student, Silvan, added,

I failed in one course out of four courses that I took, I met the professor, but he asked me to take it in another term, it was impossible as my program was in the last year. I felt much stressed.

Across cases, all encountered a stressful situation during their first term due to the tremendous quantity of assignments and homework and their degrees of problems. However, the situation was exacerbated by the treatment from professors at their host universities. Participants felt that their professors in their new academic culture did not consider their backgrounds as foreign students.

\section{Language Issues}

This theme describes the difficulties due to linguistic issues. It is noteworthy to see that the data showed that when all 24 participants arrived at their host universities, they testified that they had troubles using their English in listening, speaking, reading, and writing. These kinds of problems had prohibited them from sharing with others both inside and outside of classroom throughout their first term. Participants in this study highlighted that their English ability was not enough to help them participate in spoken presentations and active classroom participation throughout the lectures. Ayu, Debi, Diyan, Emilian, Ester, and others revealed problems they experienced while they spoke or presented in English, wrote essays, and read textbooks or research papers. In the words of Ayu, she reflected,

I could speak English, but I was not sure if my English was understood when I spoke. In the first term, I was very stressed every time I had a turn to present. I just wanted to finish it soon.

Likewise, Debi talked about her stressful situation due to the language issues: 
You know, nothing is shocking about English for me. I know how to use it. But when I was asked by my professors to present it in front of other students, it made me feel stressed during the first term.

For Emilian, he revealed that it took more time to deal with English language problems,

I feel very uncomfortable with my English writing and reading ability in the first term. I had to read several times to get into the points of what I read. It is tough.

Across participants, in this study all felt that English was an important skill of learning at a graduate level in a different culture like the Netherlands. Although they were not new to using English, they understood their English ability to be insufficient for participating in the Dutch classroom culture, leading them to be stressed during their first term.

\section{Loneliness/Isolation}

Some of the study participants were married, while some were single. The data from the interviews indicated that regardless of their marital status, the students spoke of feeling of homesickness and loneliness. During the interviews, they shared that they had feelings of loneliness and isolation from others and missed their families during the first term although they sometimes called their families through Skype. This situation resulted in their feeling as if they were not insiders at their host universities. This was exacerbated by the fact that they were not connected yet with the Indonesian student association and they had not established helpful social connections with Dutch and other international graduate students in their host universities. For example, Wiwidayu reflected,

Though I had many academic things to do here [in the host university], I still feel homesick and alone. I don't make good friends yet [in the program]. It is not easy to be separated from my family, especially my son.

Wiwidayu left her family in Indonesia and she had a 3-year old boy who stayed with her husband during her study in the Netherlands. Similarly, Ayu, who was still single, commented,

I am still single, but you know the situation here [in the program] makes me feel lonely. Even, the academic workload cannot kill my homesickness with my family. 
Across cases, feeling of homesickness and loneliness had led participants in this study to experience a feeling of social loss throughout their first semester in their host universities.

\section{No Financial Concerns}

All 24 participants reported that they had no financial concerns starting from the first term. During the interview sessions, all participants confidently expressed that financial problems did not add to the stressful life episodes as international students in the Netherlands. Aja, Nita, Ayu, Debi, Diyan, Emilian, Ester, Fikra, Hermadian, Indran, Ita, Jimmian, Murmani, Mujian, Nelasi, Rifkian, Riyana, Silvan, Wardani, Winartoni, Wiwidayu, and Zai indicated that they had enough cash to deal with their living expenditures including food, water, electricity, room rent, and clothing. For instance, Winartoni reflected on the importance of not having a financial problem,

It is not easy make my life here. But, thanks, I have enough money to support my life.

Also, Zai shared the same feeling; he said,

I am happy that I have enough money to live here [in the host university] although academic workload is too much.

The findings revealed that throughout their acculturative experiences, all participants had no money problems. Such a situation was caused by the fact that all of them received funding covering plane tickets, living allowance, tuition fees, insurance, and apartment from the Indonesian or foreign government for their master's study at their host universities.

\section{What Helps: Strategies for Coping with Acculturative Stressors}

All reported that stressors decreased after the first term. Participants generally reported that starting in the second semester, they felt less stressed and were able to adapt to the academic and non-academic stressors that they encountered, suggesting that academic and non-academic stressors are very considerable in the first term. Their fast change was motivated by a drive to be successful and was facilitated by strategies for coping with acculturative stressors including having a family network, supportive family members who live in Indonesia, and a supportive network found in the Indonesian student association on and off campus. They also commonly reported avoiding seeking counseling from the host university. 
Indonesian graduate students reported that they experienced hardships during their intercultural and continuous contacts at the host universities in the first term. Each participant expressed a need for more time to find supports in order to manage such hardships. So, after the first term, participants tried to find social support from their family members who stayed in Indonesia to manage their acculturative difficulties. They had strong support from their family. Common across all cases, Indran always contacted his family in Indonesia in order to reduce his stress working on his academic assignment. He stated,

I did not call them [his family] in the first term. I thought it would spend my time. But, in the second one [term], I called them almost every night through Skype. I even discussed my homework with them. It helps me a lot.

Similarly, Wiwidayu, who had a 3-year old boy in Indonesia, stressed the importance of support from her family,

The first term was the worse, I even forgot my boy back home. But after the first term, I realized that I needed to share what I experienced here with my husband. He [her husband] helped me a lot and even did some of my assignment.

Wiwidayu further explained that her husband did not complete assignments for her. Instead, her husband helped her to understand the assignments due to the language barriers. All other participants (Aja, Nita, Arif, Ayu, Debi, Diyan, Emilian, Ester, Fikra, Hermadian, Ita, Jimmian, Murmani, Mujian, Nelasi, Rifkian, Riyana, Silvan, Wardani, Winartoni, and Zai) shared the same story. For example, Zai called his family three times a week during his second term. He said,

I phoned my family members by using Skype three times in a week in the second term, but I did not called them much in the first term. I felt happy after telephoning them for about two or three hours."

\section{Supportive Network of Indonesian Students on and off Campus}

Indonesian graduate students experienced difficulties establishing supportive relationships with co-national students at their host universities during their first term because they struggled to manage their academic and non-academic stressors. However, after the first term, they enjoyed their 
relationships and contacts with other Indonesian students through a supportive network found in an Indonesian student association. Study participants received intense support or advice from other Indonesian international graduate students at their host universities to manage life stressors. For example, Nelasi described her experience with the support of the Indonesian student association on and off campus:

In the first term, I was so stressed by the academic things. I did not realize that here [on campus] there were a lot of Indonesian students. Luckily, I met some of them in the store...we talked a lot about life stressors. They suggested that I should come to ever Sunday's meeting. After that, I feel happy and got a lot support from them [Indonesian students].

Ester also shared the same story. She just wanted to succeed in the first term, so she spent her time working on her assignments on and off campus. She just went out if she wanted to buy food or to go to class. She said,

Every day, I just thought about finishing homework. It was in the first term. I enjoyed my time in the second one [term]. I gathered with other Indonesian students and shared my problems.

However, after the first term, she enjoyed support from other Indonesian students and Indonesian student association. The data indicated that support from co-nationals were very important for participants in this study. Their strong relationships with other Indonesian students mediated their acculturative stressors academically and socially.

\section{Avoiding Seeking Counseling from the Host University}

The participants all reported that even though they experienced hardships due to academic and non-academic stressors during their acculturative processes, no one used counseling services at their host universities to deal with their stress. One of the explanations why they did not use counseling services was because they were too reserved to discuss their difficulties with outsiders or other individuals from different cultures. In Indonesia, looking for help from others can be seen as bringing dishonor or shame to individuals. Although they were challenged by stressful life events, they managed to keep away from talking about their challenges in detail. Common across all cases, Aja commented on why he was reticent to visit counselling services at his host university. He said,

It is my problem, I don't want anyone else know it [stressors]. 
Additionally, Ita confidently expressed,

I don't think counseling center here [at her host university] [is] able to help my academic problems, it is too much. I am still able to manage it.

Also, Silvan commented,

The center is near my building, but it is close all day along. I came once there. Also, it is not good to share your problems with them, they are different.

Their reticence to share their hardships was due to their own culture. They felt that it was not good if other people knew their difficulties. They believed they were able to handle their stressful life events at their host universities. Across cases, all avoided visiting the university's counseling services. Instead, they sought for support from their family and other Indonesian students on campus.

\section{DISCUSSION}

The acculturative stress model says that clashes between the two cultures faced by acculturating persons will become acculturative stressors (Berry 2006; Berry et al., 1987). Also, prior literature has indicated that in a new educational and social setting, international students encounter the unknown, the unfamiliar, and uncertainty because of issues or factors such as race/ethnicity (Abe et al., 1998; Sato \& Hodge, 2009; Trice, 2004), social contacts and social support (Sumer, Poyrazli, \& Grahame, 2008; Trice, 2004), and English language proficiency (Fritz et al., 2008; Sumer et al., 2008; Trice, 2004). As revealed in this study, Indonesian students experienced a number of acculturative stressors or stressful life events due to exposure to a new culture throughout their first term at their host universities. It is difficult to define which stressors contributed the biggest role during students' acculturative processes because all stressors seemed to be intertwined. However, from the analysis of the data, themes emerged such as unanticipated educational stressors (e.g., unfamiliarity with content knowledge, mismatches between home and host experiences, an unexpected amount of schoolwork within a restricted time, and unaccustomedness with the Dutch classroom environment), unimagined social stressors (e.g., surprising and informal relationships between professors and students, biased treatment from professors), language issues, and loneliness or feeling isolated from others. These stressors were all intertwined and influenced participants' lives as international students at the host universities. 
Indonesian students came across what Berry (2006) and Berry et al. (1987) identified as acculturative stressors because of the dissimilarities between educational and social cultures in Indonesia and in the Netherlands. Non-stressors that modified the effects of the changes included a lack of financial concerns and strategies for coping with acculturative stressors (e.g., family network and a supportive network of Indonesian students on and off campus). Starting from their second term, in all twenty-four cases, participants reported that the feeling of stress was decreasing and no Indonesian students left their programs because all participants were determined to finish their study as the stepping stone for their future career in Indonesia, suggesting that they knew how to manage the difficulties in the host universities.

As found by the previous studies (Mukminin, 2012, Mukminin \& McMahon, 2013; Ying, 2005), acculturative stressors are most intense directly upon arrival. In this study, all acculturative stressors such as unanticipated educational stressors, unimagined social stressors, language issues, and loneliness struck Indonesian students during the first term, leading them to have hardships academically and socially. However, the results from this inquiry showed that starting from their second term, Indonesian students seemed to get courage to integrate into the academic and social cultures at their host universities, suggesting that the levels of acculturative stressors gradually reduced. Their quick acculturation was moderated by non-stressors including no financial concerns and strategies for coping with acculturative stressors.

\section{IMPLICATIONS, LIMITATIONS, AND FUTURE RESEARCH}

The acculturative problems or stressors that Indonesia graduate students encountered in this study and the strategies and the support sources that they employed to deal with stressors provide a good understanding of the acculturation processes in Dutch higher education. Therefore, faculty, staff, administrators, international offices, and university policymakers in Indonesia and in the Netherlands will find the study of interest.

For departments and universities in the Netherlands admitting international graduate students, the findings of this study reveal that because of the differences in education systems between Indonesia and the Netherlands, Indonesian students experienced acculturative stressors in the first semester, but their acculturative stressors gradually reduced after the first semester. To deal with the acculturative stressors in the first term, universities could set policies or programs for serving international graduate students to learn the cultural norms and traditions of Dutch higher education including study requirements, classroom behaviors, class dynamics, academic 
workload, the nature of relationships with professors, and expectations upon arrival and throughout the first semester.

For faculty members and academic advisers, the findings of the study can be employed to better support international graduate students in preparing for successful acculturative processes to their university life in the Netherlands. International graduate students will not always come to their faculty members and academic advisers. Many wait until faculty members and academic advisers initiate the interactions. Faculty members and academic advisers should connect with international graduate students by facilitating wellorganized consultations with international graduate students to talk about their concerns or offering structured academic advising throughout their office hours for their graduate students (e.g., provide consistent feedback).

This inquiry has several limitations concerning the results. First, the sample in this inquiry may not be representative of all Indonesian international graduate students in the Netherlands. There may be dissimilarities of acculturative experiences encountered by Indonesian students who are registered in dissimilar programs, post-doctoral programs, or non-degree programs. Future inquiry may consist of a larger sample of Indonesian international graduate students from diverse universities in the Netherlands. Second, this inquiry was limited to 24 Indonesian international master's students at two Dutch public research universities in the northern part of the Netherlands. In future inquiry, Dutch professors' viewpoints on Indonesian international graduate students' acculturative processes would be helpful. Additionally, Indonesian graduate students who participated all received various scholarships, so other researchers can replicate and extend this inquiry to self-funding graduate students from Indonesia or other countries.

\section{REFERENCES}

Abe, J., Talbot, D. M., \& Geelhoed, R. J. (1998). Effects of a peer program on international student adjustment. Journal of College Student Development, 39(6), 539-547.

Abrar, M., Mukminin, A., Habibi, A., Asyrafi, F, Makmur, \& Marzulina, L. (2018). "If our English isn't a language, what is it?" Indonesian EFL student teachers' challenges speaking English. The Qualitative Report, 23(1), 129-145.

Berry, J. W. (2006). Acculturative stress. In P. T. P. Wong \& L. C. J. Wong (Eds.), Handbook of multicultural perspectives on stress and coping: International and cultural psychology series (pp. 287-298). New York: Springer. 
Berry, J. W., Kim, U., Minde, T., \& Mok, D. (1987). Comparative studies of acculturative stress. International Migration Review, 21(3), 491511.

Creswell, J. W. (2007). Qualitative inquiry and research design: Choosing among five traditions (2nd ed.). Thousand Oaks, CA: Sage.

Easterly, W. R. (2001). The elusive quest for growth: Economists' adventures and misadventures in the tropics. London: MIT Press.

Fritz, M. V., Chin, D., \& DeMarinis, V. (2008). Stressors, anxiety, acculturation, and adjustment among international and North American students. International Journal of Intercultural Relations, $32,244-259$.

Goodman, A. E. (1996). What foreign students contribute. The Chronicle of Higher Education, 42, A52.

Heggins, W. J., \& Jackson, J. F. L. (2003). Understanding the collegiate experience for Asian international students at a Midwestern research university. College Student Journal, 37(3), 379-391.

Institute of International Education. (2017). Open Doors 2017 report: Information and data tables. Retrieved from http://www.iie.org Jochems, W., Snipe, J., Smid, H. J., \& Verweij, A. (1996). The academic progress of foreign students: Study achievement and study behavior. Higher Education, 31, 325-340.

Kuh, G. D., Gruce, T., Shoup, R., Kinzie, J., \& Gonyea, R. M. (2007). Unmasking the effects of student engagement on college grades and persistence. Paper presented at the annual meeting of the American Educational Research Association, April 2007, Chicago, IL.

Lee, J. J., \& Rice, C. (2007). Welcome to America? International student perceptions of discrimination. Higher Education, 53, 381-409.

Li, A., \& Gasser, M. B. (2005). Predicting Asian international students' sociocultural adjustment: A test of two mediation models. International Journal of Intercultural Relations, 29(5), 561-576.

Merriam, S. B. (1998). Qualitative research and case study applications in education. San Francisco, CA: Jossey-Bass.

Moustakas, C. (1994). Phenomenological research methods. Thousand Oaks, CA: Sage.

Mukminin, A. (2012). Acculturative experiences among Indonesian graduate students in US higher education: Academic shock, adjustment, crisis, and resolution. Excellence in Higher Education Journal, 3(1), 14-36.

Mukminin, A., Ali, R. M., \& Fadloan, M. J. (2015). Voices from within: Student teachers' experiences in English academic writing socialization at one Indonesian teacher training program. The Qualitative Report, 20(9), 1394-1407. 
Mukminin, A., Kamil, D., Muazza, M., \& Haryanto, E. (2017). Why teacher education? Documenting undocumented female student teachers' motives in Indonesia: A case study. The Qualitative Report, 22(1), 309-326.

Mukminin, A., \& McMahon, B. J. (2013). International graduate students' cross-cultural academic engagement: Stories of Indonesian doctoral students on American campus. The Qualitative Report, 18(69), 119.

Mukminin, A., Rohayati, T., Putra, H. A., Habibi, A., \& Aina, M. (2017). The long walk to quality teacher education in Indonesia: Student teachers' motives to become a teacher and policy implications. Elementary Education Online, 16(1), 35-59.

Nguyen, D. J., \& Larson, J. B. (2017). Exploring the influence of student affairs on adjustment and adaptation for Indonesian graduate students. Journal of International Students, 7(4), 1010-1029.

Nilsson, J. E., Butler, J., Shouse, S., \& Joshi, C. (2008). The relationships among perfectionism, acculturation, and stress in Asian international students. Journal of College Counseling, 11(2), 147158.

Patton, M.Q. (1990). Qualitative evaluation and research methods. Thousand Oaks, CA: Sage.

Polkinghorne, D. E. (1989). Phenomenological research methods. In S. R. Valle, S. Halling, \& J. F. T. Bugental (Eds.), Existentialphenomenological perspectives in psychology (pp. 41-60). New York: Plenum.

Poyrazli, S., Kavanaugh, P, R., Baker, A., \& Al-Timimi, N. (2004). Social support and demographic correlates of acculturative stress in international students. Journal of College Counseling, 7, 73-82.

Sato, T., \& Hodge, S. R. (2009). Asian international doctoral students' experiences at two American universities: Assimilation, accommodation, and resistance. Journal of Diversity in Higher Education, 2(3), 136-148.

Sumer, S., Poyrazli, S., \& Grahame, K. (2008). Predictors of depression and anxiety among international students. Journal of Counseling \& Development, 86, 429-437.

Trice, A. G. (2004). Mixing it up: International graduate students' social interactions with American students. Journal of College Student Development, 45(6), 671-687.

Vinke, A. A., \& Jochems, W. (1993). English proficiency and academic success in international postgraduate education. Higher Education, 26, 275-285. 
Wilton, L., \& Constantine, M. G. (2003). Length of residence, cultural adjustment difficulties, and psychological distress symptoms in Asian and Latin American international students. Journal of College Counseling, 6, 177-186.

World Bank. (2002). Constructing knowledge societies: New challenges for tertiary education. New York: Author.

Yeh, C. J., \& Inose, M. (2003). International students' reported English fluency, social support satisfaction, and social connectedness as predictors of acculturative stress. Counseling Psychology Quarterly, 16(1), 15-28.

Ying, Y. (2005). Variation in acculturative stressors over time: A study of Taiwanese students in the United States. International Journal of Intercultural Relations, 29, 59-71.

Zhai, L. (2002). Studying international students: Adjustment issues and social support. San Diego: Office of Institutional Research, San Diego Community College District. (ERIC Document Reproduction Service No. ED 474481).

AMIRUL MUKMININ, PhD, is a faculty member in the Faculty of Education,
Jambi University, Indonesia. He holds a PhD from Florida State University in
Educational Leadership and Policy Studies and an MS in educational sciences from
Groningen University, the Netherlands. He received a Fulbright scholarship to pursue
his PhD and was an Erasmus Mundus postdoctoral researcher at the University of
Groningen, the Netherlands. He received a 2016-2017 Fulbright Senior Research at
Claremont Graduate University, California. He is particularly interested in
educational policy, international education policy, teacher policy reforms, the
standardized exam policy reforms, English/Indonesian language policy reforms, and
bilingual/multilingual education policy, which will influence educational outcomes
for underachieving student populations and family.
$\begin{aligned} & \text { amirul.mukminin@unja.ac.id } \\ & \text { pand: }\end{aligned}$
Manuscript submitted: March 8, 2018
Accepted for publication: March 29, 2019 